\title{
Transgenic mice for the establishment of histidinol-resistant embryonic fibroblast feeder
}

layers

\author{
REBECCA M. TUCKER AND DAVID T. BURKE ${ }^{1}$ \\ Department of Human Genetics, University of Michigan, Ann Arbor, Michigan 48109, USA
}

\begin{abstract}
Gene targeting in mouse embryonic stem cells generates mutations by replacing an endogenous chromosomal region with a copy disrupted by a selectable genetic marker. The most commonly used selectable marker is the bacterial neor gene, which confers resistance in mammalian cells to the antibiotic G418. Use of an alternative selectable marker, the Salmonella typhimurium gene hisD, should provide expanded applications for gene targeting. The hisD gene encodes the protein histidinol dehydrogenase, which catalyzes the conversion of histidinol to the amino acid histidine. Histidinol is toxic to mammalian cells, while histidine is an essential mammalian amino acid. Consequently, growth selection in cultures with media containing histidinol in place of histidine occurs by both histidine starvation and histidinol poisoning. The hisD selection is being tested for potential use in gene targeting experiments with mouse embryonic stem (ES) cells. Currently, most successful gene targeting experiments use primary embryonic fibroblast feeder layers, which assist in the maintenance of the pluripotential state of the embryonic stem cells. To support ES cell stability under histidinol selection, mice transgenic for the $S$. typhimurium hisD gene have been produced and used to generate embryonic fibroblast feeder cells. The transgenic embryonic fibroblasts survive under a wide range of histidinolcontaining growth conditions and support growth of ES cell cultures.-Tucker, R. M., Burke, D. T. Transgenic mice for the establishment of histidinolresistant embryonic fibroblast feeder layers. FASEB J. 10, 1641-1645 (1996)
\end{abstract}

Key Words: embryonic stem cells $\cdot$ gene targeting $\cdot$ selectable marker

THE USE OF TARGETED GENE modification via homologous recombination in mouse embryonic stem (ES) ${ }^{2}$ cells has greatly expanded the power of the mouse as a model experimental system. Initial gene targeting experiments utilized mutations in endogenous selectable genes as methods for eliminating nontargeted cells $(1,2)$. The development of bacterial drug resistance genes as mammalian selectable markers has increased the applicability of this technology to allow for targeting any DNA sequence $(3-6)$. The most widely used of these is the neomycin resistance gene, aminoglycosidase phosphotransferase $\left(n e o^{r}\right)$, from the bacterial transposon Tn5. The neo gene product confers resistance in mammalian cells to the drug G418. However, there are instances when an alternative dominant selectable marker is needed. For example, an alternative selection is essential when the neor gene is already present in the ES cell line and an additional recombination event is attempted (7-10) or more than one selectable marker is needed to increase the efficiency of selection of the recombination event.

An alternative selective scheme uses the replacement of L-histidine (his) with L-histidinol (hol) in the growth media of normal cells. The replacement of histidine with histidinol is toxic to mammalian cells by two mechanisms. Because histidine is an essential amino acid in mammals, its removal results in rapid cell starvation (11). Second, the presence of histidinol prevents histidine incorporation during protein synthesis by directly competing for the histidyl-tRNA synthetase (12). Both lethal effects can be relieved by intracellular expression of the bacterial biosynthetic protein histidinol dehydrogenase (Salmonella typhimurium, hisD, EC 1.1.1.23). The hisD gene is the final step of the histidine biosynthetic pathway and is essential for the $\mathrm{NAD}^{+}$-dependent conversion of histidinol to histidine. When originally described, the his $D$ growth selection was tested by transfection into three mammalian cell lines and selective growth in a histidine-free, histidinol-containing media (13). It has since been used in DNA transfer experiments (14-18), and was tested as a selectable marker in recombination experiments in a rat fibroblast cell line (19). However, hisD has yet to be tested for its suitability as a selective marker in embryonic stem cells.

The maintainance of totipotent ES cells is known to be enhanced by factors secreted from mitotically inactivated primary mouse embryonic fibroblast (MEF) feeder layers

\footnotetext{
${ }^{\mathrm{l}}$ To whom correspondence should be addressed, at: Department of Human Genetics, University of Michigan Medical School, 1150 W. Medical Center Dr., Ann Arbor, MI 48109, USA.

2 Abbreviations: ES, embryonic stem; MEF, mouse embryonic fibroblast; his, L-histidine; hol, L-histidinol; RT-PCR, reverse transcription-polymerase chain reaction; PFG, pulsed-field gel.
} 
$(20,21)$. The feeder layers must survive any subsequent selection strategy performed on the ES cells. Consequently, in the histidinol selection method, feeder fibroblasts must be isolated from embryos that express the his $D$ gene. To this end, we have produced mice transgenic for the his $D$ gene under the control of a mammalian promoter. We have tested embryonic fibroblasts from these mice for their ability to live in histidine-depleted, histidinol-containing media (DMEM-his +hol) and to support normal and selected ES cell growth.

\section{METHODS}

\section{Generation and analysis of transgenic mice}

Transgenic mice were produced by the method of Hogan et al. (22) The 3.3 kilobase DNA fragment used for microinjection of mouse pronuclei was generated by an $A c c \mathrm{~L} / E c o R I$ restriction digest of plasmid pSV2his (kindly provided by S. Hartman) (Fig. 1). The fragment was isolated from a preparative gel of low-melt agarose (SeaPlaque, FMC), and purified on a Nucleobond AX cartridge (The Nest Group) and resuspended in injection buffer (10 mM Tris, $\mathrm{pH} 7.4,0.25 \mathrm{mM}$ EDTA) at a concentration of $1 \mathrm{ng} / \mathrm{ml}$. Microinjection was performed on 350 single cell embryos recovered from superovulated $\mathrm{C} 57 \mathrm{Bl} / 6 \times \mathrm{SJL}$ females mated with $\mathrm{C} 57 \mathrm{Bl} / 6 \times \mathrm{SJL}$ males. After culturing overnight, 250 embryos were transferred to pseudopregnant BALB/c females who had been mated to vasectomized males (obtained from Charles River Laboratories, Wilmington, Mass.).

Sixty candidate pups were screened for presence of the transgene by a polymerase chain reaction (PCR) assay performed on DNA extracted from tail cuttings (23). The PCR assay is specfic for the hisD gene and used the following primers: 5'-GCTGATGAAATCCTCTATGC-3' (F1), 5'TAGCAGTATAGCCATAGGTCG-3' (R1). Reactions were performed in a Biometra UNO thermocycler with the following cycling conditions: $94^{\circ} \mathrm{C} 5 \mathrm{~min}$, then 30 cycles of $94^{\circ} \mathrm{C} 30 \mathrm{~s}, 60^{\circ} \mathrm{C} 30 \mathrm{~s}, 72^{\circ} \mathrm{C} 30 \mathrm{~s}$, followed by a $10 \mathrm{~min}$ extension at $72^{\circ} \mathrm{C}$. PCR products were resolved on a $1.2 \%$ agarose, $0.5 \times \mathrm{TBE}$ gel to assay for the expected $634 \mathrm{bp}$ band. Two of the 60 pups were positive for the hisD sequence. These positive founder mice and representative transgenic progeny were further analyzed by hybridization analysis of genomic DNA (24). Transgene copy number was determined by comparison of hybridization intensity to pSV2his plasmid in C57Bl/6J mouse DNA at a calculated molar equivalent of 1 , 10 , or 100 copies. Based on the plasmid size of $5.6 \mathrm{~kb}, 9.6 \mathrm{pg}$ of plasmid DNA was added to $10 \mathrm{mg}$ of $\mathrm{C} 57 \mathrm{Bl} / 6 \mathrm{~J}$ mouse DNA for each genome equivalent.
RNA hybridization analysis and reverse transcription-PCR (RTPCR) was performed on RNA extracted from tissues dissected from a typed heterozygous line A offspring. Total RNA was prepared by a standard RNAsol protocol (Tel-Test). PolyA RNA was purified from 150-250 mg total RNA by use of Oligo dTex columns (Qiagen, Chatsworth, Calif.) and was run on a $1 \%$ agarose/methyl mercury denaturing gel (25). RT-PCR was performed on lmg total RNA with the following primers and cycling conditions: $5^{\prime}$ CTGTGGTGTGACATAATTGG-3' (F2), 5'-GATCAGTTCCGTGATATGTAG-3' (R2); PCR conditions: $94^{\circ} \mathrm{C} 5 \mathrm{~min}, 35$ cycles of $94^{\circ} \mathrm{C} 30 \mathrm{~s}, 55^{\circ} \mathrm{C} 30 \mathrm{~s}, 72^{\circ} \mathrm{C}$ 30 s. Resulting PCR products were analyzed on a $5 \%$ acrylamide gel. Because this second primer pair spans an intron, genomic DNA should yield a product of 587 bp while reverse transcribed RNA should give a result of $517 \mathrm{bp}$.

\section{Cell culture}

MEFs were prepared as follows (26). Two transgenic female mice were bred with one transgenic male littermate and checked for vaginal plugs daily. A control breeding of C57Bl/6 mice was also performed. At 14 days after observation of vaginal plug, females were killed and embryos were removed. Nine transgenic-derived embryos were collected and pooled, and 10 control embryos were collected separately into sterile phosphate-buffered saline (PBS). Whole embryo carcasses were minced and treated with $0.05 \%$ trypsin (Gibco, Gaithersburg, Md.) until cells were dispersed as visualized under a microscope. Cells were plated into DMEM, $10 \%$ fetal bovine serum (FBS) for two passages. After the second passage, $5 \times 10^{4}$ cells were plated into DMEM-his (Gibco, custom formulation), $10 \%$ FBS, that was supplemented with either histidine to standard concentration levels (i.e., complete media) or varying concentrations of histidinol (Sigma Chemical Co., St. Louis, Mo.). After $24 \mathrm{~h}$, media was replaced with fresh media of same histidinol concentration, and after 3 days the total cell number was determined by counting live cells on a hemocytometer in the presence of Trypan blue.

\section{RESULTS}

\section{Transgene copy number}

The copy number of the his $D$ transgene was determined by Southern hybridization analysis using the hisD gene fragment 1 as a probe (Fig. 1 and Fig. 2). Internal digestion of a tandem array of pSV2his integrants results in a $3.3 \mathrm{~kb}$ band. The $7.2 \mathrm{~kb}$ band in founder $\mathrm{A}$ and $\mathrm{A}-$-line progeny represents a unique junction fragment. Three of

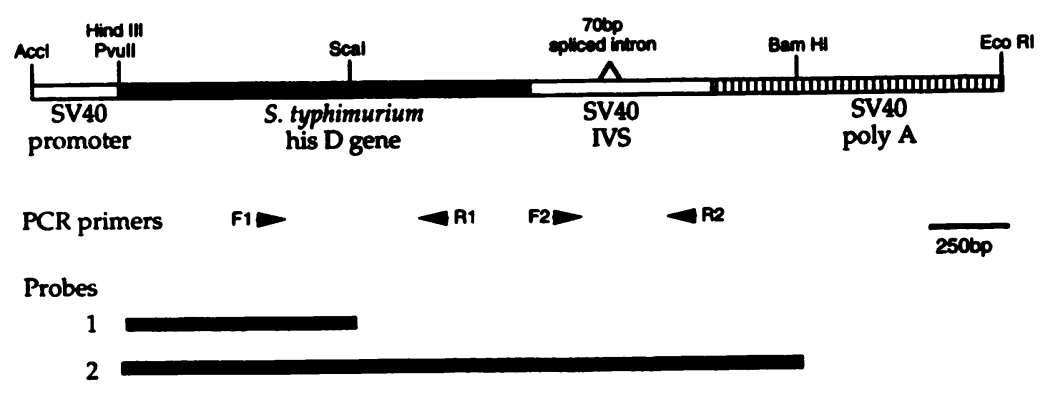

Figure 1. A map of the $h i s D$ transgene expression construct. The construct was isolated as a $3.3 \mathrm{~kb} A c c \mathrm{I} / E c c R I$ fragment from pSV2his. Probe 1 was used for DNA hybridization analysis. Probe 2 was used for mRNA hybridization analysis. PCR primer pair Fl and Rl was used for screening genomic DNA for transgenic progeny. PCR primer pair F2 and R2 was used for reverse transcription-PCR analysis of RNA. The spliced region in the intervening sequence (IVS) is 70 bp and lies between the $F 2$ and $R 2$ primers. 


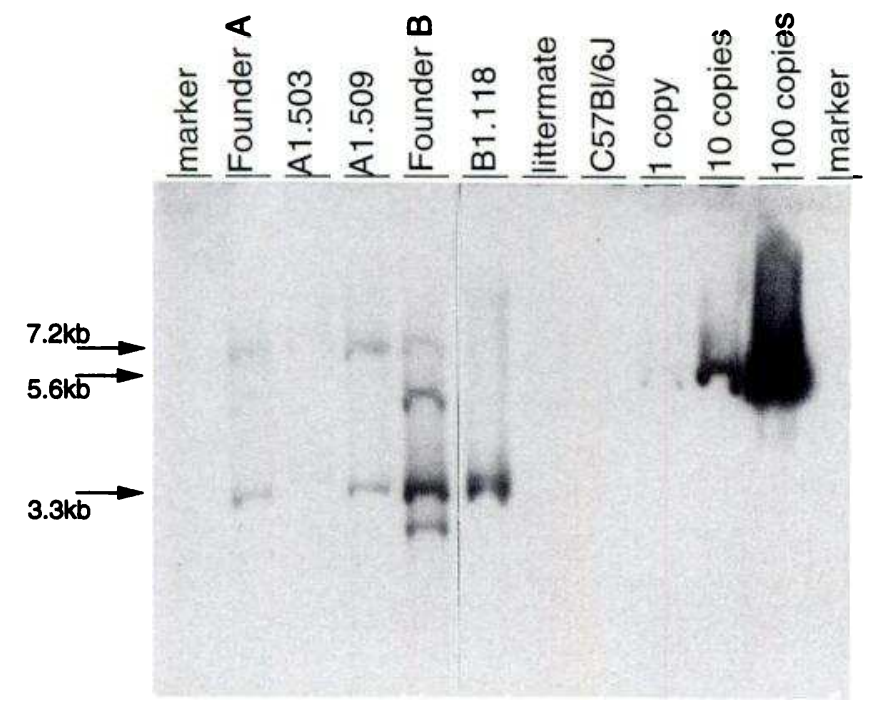

Figure 2. Southern analysis of BamHI-digested DNA from transgenic founder and heterozygous progeny. After resolution of restriction enzymedigested DNA samples ( $10 \mathrm{mg}$ each) on a $1 \%$ agarose, $0.5 \times \mathrm{TBE}$ gel, DNA was transferred to a nylon membrane for hybridization. Negative controls include a nontransgenic littermate of founder $\mathrm{A}$ and a $\mathrm{C} 57 \mathrm{Bl} / 6 \mathrm{~J}$ female. Copy number controls are $\mathrm{C} 57 \mathrm{~B} \mathrm{~V} / 6 \mathrm{~J}$ genomic DNA mixed with 1,10 , or 100 gene equivalents of pSV2his plasmid. Using probe 1 (Fig. 1), the digestion of a tandem array of integrated pSV2his fragments results in a common $3.3 \mathrm{~kb}$ band. The $7.2 \mathrm{~kb}$ band in A-line mice represents a unique junction fragment. The $5.6 \mathrm{~kb}$ band in the copy number control lanes is the size of the linearized pSV2his plasmid.

the four bands seen in founder $B$ are not transmitted to subsequent litters, while a unique $3.4 \mathrm{~kb}$ junction fragment is found in B-line progeny (Fig. 2 and data not shown). The $5.6 \mathrm{~kb}$ band in the copy number control lanes is the size of the linearized pSV2his plasmid. By comparison of the experimental hybridization intensity with the known copy number controls, it was estimated that approximately three to five copies of the injected DNA integrated into the mouse genome in transgene line $A$, and eight to ten copies integrated into transgene line B. The copy number estimation was confirmed by additional Southern hybridization analysis using pulsed-field gel (PFG) examination of line A DNA digested with four restriction enzymes that do not digest within the transgene. On the PFG hybridization, the smallest single band was a $13.5 \mathrm{~kb}$ EcoRI fragment, indicating that four full copies of pSV2his at most had integrated in a tandem array (data not shown). The $B$ line was not examined by PFG and received no further analysis in this study.

\section{Tissue distribution of hisD RNA transcript}

Northern blot analysis and hybridization with the his $D$ gene probe 2 of polyA-purified RNA demonstrates the presence of a transcript of the predicted size $(1.5 \mathrm{~kb})$ in kidney, heart, and brain (Fig. 3). No signal is detected in lung or spleen. The spleen RNA sample was too degraded to give a reliable result and the lung sample was underloaded relative to the other samples. The bands at
$>10 \mathrm{~kb}$ were determined to be cross-hybridization with residual genomic DNA.

To confirm this result and to test for transcription at a higher sensitivity, RT-PCR analysis of total RNA from the same tissues and liver was performed. All tissues tested, except liver, showed the presence of a RT-PCR product specific for his $D$ transcription (Fig. 4).

\section{Growth of transgenic primary embryonic fibroblasts in selective media}

Transgenic embryonic fibroblasts were prepared from embryos of two heterozygous transgenic female that were bred to a heterozygous male. Three-quarters of the embryos will maintain the transgene in such matings. A nontransgenic mating of $\mathrm{C} 57 \mathrm{Bl} / 6 \mathrm{~J}$ mice produced control embryos. Embryonic cells were grown in either complete growth media or selective media (DMEM-his) containing varying histidinol concentrations $(0.125$ to $8 \mathrm{mM})$ in place of histidine. Cell count was determined after 3 days on triplicate samples at each growth condition and relative cell survival (RCS) was calculated by dividing the number of cells that grew in selective media by the number that grew in complete media (histidine-supplemented DMEM, DMEM-his + his) (Fig. 5). Nontransgenic C57 $\mathrm{Bl} / 6 \mathrm{~J}$ cells are almost completely absent after 3 days in media containing histidinol concentrations of $0.5 \mathrm{mM}$ or greater. Transgenic-derived cells grow within $80 \%$ of

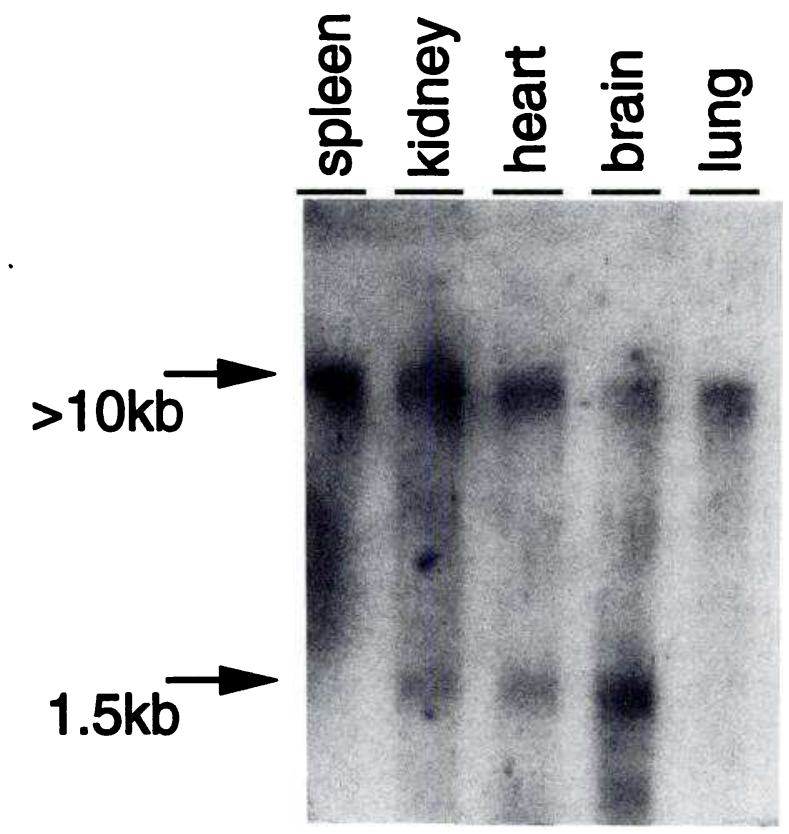

Figure 3. Confirmation of his $D$ transcription in transgenic animals by Northern blot analysis of polyA RNA. For each tissue, polyA RNA was prepared from $250 \mathrm{mg}$ total RNA, except lung, in which $150 \mathrm{mg}$ was used. The entire poly A-purified sample was loaded onto a $1.5 \%$ agarose-methyl mercury gel, transferred to nylon membrane, and hybridized with probe 2 (Fig. 1). The $1.5 \mathrm{~kb}$ band represents full-length transcription of the his $D$ gene from the SV40 promoter. The bands at $>10 \mathrm{~kb}$ result from cross-hybridization with genomic DNA, which copurified with the mRNA sample. 


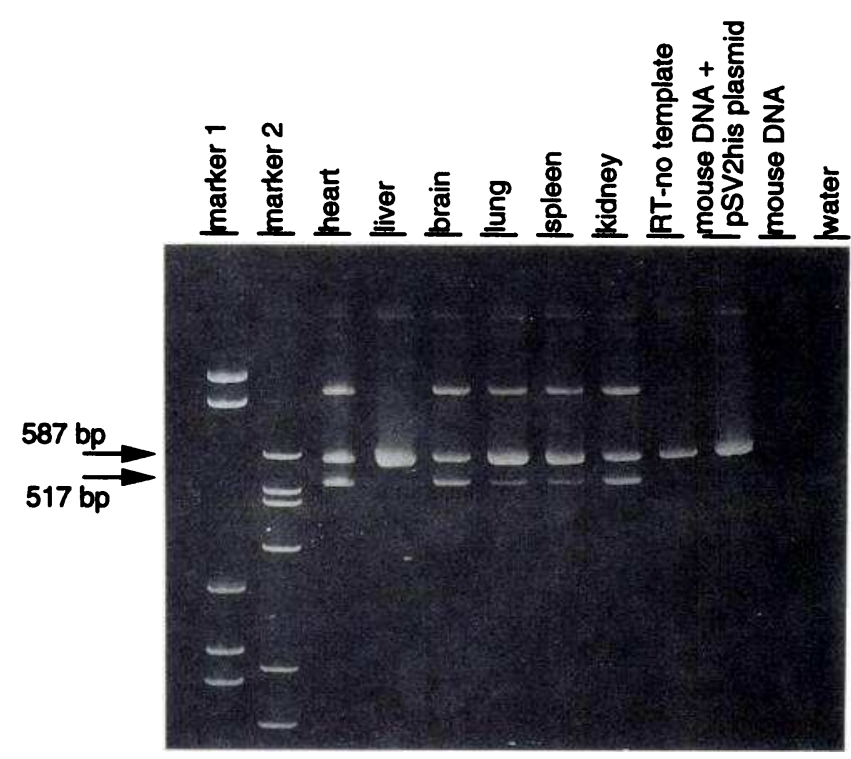

Figure 4. Confirmation of hisD transcription in transgenic animals by reverse transcription-PCR analysis. The 517 bp product is from reverse transcribed mRNA, while the 587 bp product is derived from genomic DNA. PCR primers used were F2 and R2 shown in Fig. 1. Control samples include: 1) "RT-no template," reverse transcription in the absence of RNA, 2) "mouse DNA + pSV2his plasmid," positive PCR amplification control (100 ng C57Bl/6J DNA and $1 \mathrm{ng}$ pSV2his plasmid), and 3) "mouse DNA," negative PCR amplification control (100 ng C57Bl/6J DNA). The marker samples are pBluescript DNA digested with Sau3A (marker 1) and pBluescript DNA digested with $M s p I$ (marker 2).

normal levels in ranges of 0.5 to $4 \mathrm{mM}$ histidinol. This small drop is presumed to be a result of approximately one-quarter of the cells being nontransgenic. The slightly poorer growth of transgenic fibroblasts in $0.125 \mathrm{mM}$ histidinol could be the result of his $D$-mediated conversion of histidinol to histidine not reaching a threshold concentration for cell survival.

\section{DISCUSSION}

We have produced transgenic mice carrying the $S$. $t y$ phimurium hisD gene, and tested MEFs from these mice for gene transcription and for their ability to grow in histidine-deficient, histidinol-containing media. The results demonstrate a large range of selective growth conditions in which these cells survive. Transgenic MEF growth in DMEM-his thol media is vigorous and shows no indication of histdinol toxicity to at least $4 \mathrm{mM}$. Normal cells die rapidly in histidine-deficient media supplemented with histidinol at any concentration.

The hisD gene may prove to be of use in gene targeting experiments where an alternative to the $n e o^{r}$ gene is needed. ES cells in which one allele of a gene has been inactivated by a $n e o^{r}$ gene insertion and the second allele must be targeted with a different selectable marker is one such example. More complex targeting reactions, such as the "hit and run" (7) or the "plug and socket" (27) strategies that introduce modifications via two recombination events, may also benefit from this new selection scheme. Targeted recombination events that use larger constructs might be enhanced by having two simultaneous selections that bracket the desired integration region. Finally, in many experimental programs, the cost of the drug G418 may be prohibitive. The his $D$ selection significantly reduces the problem of selective media costs. Histidinol, being an amino acid precursor, is inexpensive and readily available from numerous sources. At the $4 \mathrm{mM}$ hisD selection level, the cost of histidinol is approximately $\$ 0.85 / 1$ of media vs. $\$ 70 / 1$ for G418 selection media. Lowered cost of reagents will be important for experiments involving large-scale screens for ES recombinant clones.

The hisD transgenic mice may have uses beyond the production of histidinol-resistant MEFs. Histidinol has been previously shown to be a potent inibitor of protein synthesis in mammalian cells. This, in turn, arrests cells in the $G_{0}$ phase of cell division. Certain tumor cells can overcome histidinol-induced $G_{0}$ arrest and continue to proliferate. In vitro and in vivo tests have shown that some chemotherapeutic agents that target proliferating cells are more effective at removing the tumor cells from the population when used in conjunction with histidinol (28-30). Due to the arrest of the normal cells in their quiescent state, these cells are protected from the toxicity of the chemotherapeutic drug. The his $D$ transgenic mice have the capability to convert histidinol to histidine, potentially circumventing the protective effects of histidinol and providing an in vivo model system for histidinol tumor inhibition studies.

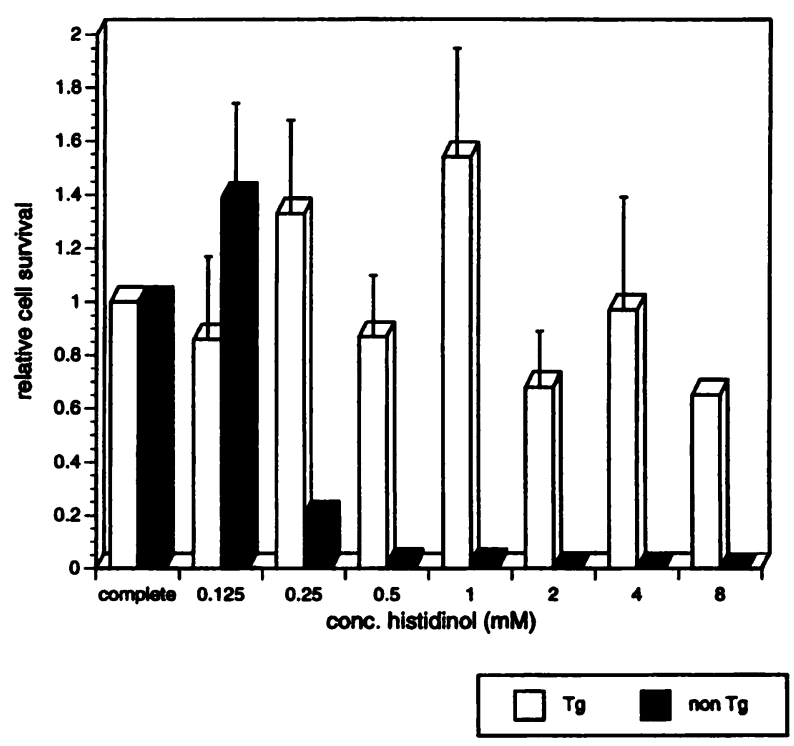

Figure 5. Relative cell survival of MEF cells from transgenic ( $\mathrm{Tg}_{\mathrm{g}}$ or $\mathrm{C57BV} / 6 \mathrm{~J}$ (non $\mathrm{Tg}$ ) embryos. Triplicate samples of cells were cultured in DMEM without histidine, supplemented with either histidine at $42 \mathrm{mg} / \mathrm{l}$ ("control") or a range of concentrations of histidinol. After 3 days growth, cell count was determined and plotted relative to unselected survival in complete media. Error bars represent the standard error. 
Other biochemical studies may also profit from the use of his $D$-containing cells. The mode of histidinol toxicity to mammalian cells is known to be the reversible binding of histidinol to the histidine tRNA-synthetase. Cell lines that can convert histidinol to histidine may serve as useful controls for analyzing the competition of amino acids and their precursors for these tRNA charging enzymes.

It is expected that the development of hisD as an additional selective marker in ES cell experiments may increase the applicability of such experimental strategies. Hygromycin has recently been used as an alternative marker in addition to the standard neo ${ }^{r}$ selection (31). The availabilty of these three selection schemes for ES cell "knockout" experiments will certainly expand the versatility of gene targeting.

Transgenic line A has been bred to homozygosity for the hisD transgene locus. In addition, MEFs that are doubly resistant to histidinol and G418 have been produced by intercrossing transgenic line $A$ with available neor transgenic mice (32). These dual selection MEFs are also able to support strong growth of mouse ES cells. ES cells grown in selective media (DMEM-his +hol, $0.25 \mathrm{mM}$ and greater) are rapidly eliminated. Conversely, ES cells that have been transfected with a recombinant plasmid (pB875), derived from the promoter region of pMClneopolA (2) and the hisD coding region from pSV2his, grow at $42 \%$ RCS in selective media (DMEMhis +hol, $0.25 \mathrm{mM}$ ).

We thank Thom Saunders and the Transgenic Animal Core Facility of the University of Michigan for instruction and resources used in the generation of these mice. This project receives grant support from the March of Dimes Birth Defects Foundation (Basil O'Connor Starter Scholar Award). D.T.B. is a recipient of support from the Searle Scholars Program of the Chicago Community Trust.

\section{REFERENCES}

1. Doetschman, T., Gregg, R. G., Maeda, N., Hooper, M. L., Melton, D. W. Thompson, S., and Smithies, O. (1987) Targeted correction of a mutant HPRT gene in mouse embryonic stem cells. Nature (London) 330, 576-578

2. Thomas, K. R., and Capecchi, M. R. (1987) Site-directed mutagenesis by gene targeting in mouse embryo-derived stem cells. Cell 51, 503-512

3. Joyner, A. L., Skarnes, W. C., and Rossant, J. (1989) Production of a mutation in the mouse En-2 gene by homologous recombination in embryonic stem cells. Nature (London) 338, 153-156

4. Koller, B. H., and Smithies, O. (1989) Inactivating the b-2 microglobulin in mouse embryonic stem cells by homologous recombination. Proc. Natl. Acad. Sci. USA 86, 8932-8935

5. Zimmer, A., and Gruss, P. (1989) Production of chimaeric mice containing embryonic stem cells carrying a homoeobox Hoxl.1 allele mutated by homologous recombination. Nature (London) 338, 150-153

6. Johnson, R. S., Sheng, M., Greenberg, M. E., Kolodner, R. D., Papaioannou, V. E., and Speigelman, B. M. (1989) Targeting of nonexpressed genes in embryonic stem cells via homologous recombination. Science 245 , 1234-1236

7. Bautista, D., and Shulman, M. J. (1993) A hit and run system for introducing mutations into the IgH chain locus of hybridoma cells by homologous recombination. J. Immunol. 15 1, 1950-1958
8. te Riele, H., Maandag, E. R., Clark, A., Hooper, M., and Berna, A. (1990) Consecutive inactivation of both alleles of the pim-l proto-oncogene by homologous recombination in embryonic stem cells. Nature (London) 348, 649-651

9. Valancius, V., and Smithies, O. (1991) Testing an In-Out targeting procedure for making subtle genomic modifications in mouse embryonic stem cells. Mol. Cell. Biol. 11, 1402-1408

10. Askew, G. R., Doetschman, T., and Lingrel, J. B. (1993) Site-directed point mutations in embryonic stem cells: a gene-targeting Tag-and -Exchange strategy. Mol. Cell. Biol. 13, 4115-4124

11. Scornik, O. A., Ledbetter, M. L. S., and Malter, J. S. (1980) Role of aminoacylation of histidyl-tRNA in the regulation of protein degradation in Chinese hamster ovary cells. J. Biol. Chem. 255, 6322-6329

12. Hansen, B.S., Vaughan, M. H., and Wang, L.-J. (1972) Reversible inhibition by histidinol of protein synthesis in human cells at the activation of histidine. J. Biol. Chem. 247, 3854-3857

13. Hartman, S. C., and Mulligan, R. C. (1988) Two dominant acting selectable markers for gene transfer studies in mammalian cells. Proc. Natl. Acad. Sci. USA 85, 8047-8051

14. Li, Y.-P., Tomanin, R., Smiley, J. R., and Bacchetti, S. (1993) Generation of a new adenovirus type 12-inducible fragile site by insertion of an artificia U2 locus in the human genome. Mol. Cell. Biol. 13, 6064-6070

15. von Melchner, H., Reddy, S., and Ruley, H. E. (1990) Isolation of cellular promoters by using a retrovirus promotor trap. Proc. Nall. Acad. Sci. USA 87 , 3733-3737

16. Farr, C., Fantes, J., Goodfellow, P., and Cooke, H. (1991) Functional reintroduction of human telomeres into mammalian cells. Proc. Natl. Acad. Sci. USA 88, 7006-7010

17. Warburton, D., Gersen, S., Yu, M.-T., Jackson, C., Handelin, B., and Housman, D. (1990) Monochromosomal rodent-human hybrids from microcell fusion of human lymphoblastoid cells containing an inserted dominan selectable marker. Genomics 6, 358-366

18. Brown, F. L., Tahaoglu, E., Graham, G. J., and Maio, J. J. (1993) Inducible transcriptional activation of the human immunodeficiency virus long terminal repeat by protein kinase inhibitors. Mol. Cell. Biol. 13, 5245-5254

19. Hanson, K. D., and Sedivy, J. M. (1995) Analysis of biological selections for high-efficiency gene targeting. Mol. Cell. Biol. 15, 45-51

20. Pease, S., Braghetta, P., Gearing, D., Grail, D., and Williams, R. L. (1990) Isolation of embryonic stem cells in media supplemented with recombinan leukemia inhibitory factor. Dev. Biol. 141, 344-352

21. Ramirez-Solis, R., Davis, A. C., and Bradley, A. (1993) Gene targeting in embryonic stem cells. Methods Enzymol. 224, 855-890

22. Hogan, B., Costantini, F., and Lacy, E. (1986) Manipulating the Mouse Embryo: A Laboratory Manual, Cold Spring Harbor Laboratory, Cold Spring Harbor, New York

23. Miller, S. A., Dykes, D. D., and Polesky, H. F. (1988) A simple salting out procedure for extracting DNA from human nucleated cells. Nucleic Acids Res. 16,1215

24. Church, G. M., and Gilbert, W. (1984) Genomic sequencing. Proc. Natl. Acad. Sci. USA 81, 1991-1995

25. Bailey, J. M., and Davidson, N. (1976) Methylmercury as a reversible denaturing agent for agarose gel electrophoresis. Anal. Biochem. 70, 75-85

26. Robertson, E. J. (1987) Embryo-derived stem cell lines. In Teratocarcinomas and Embryonic Ttem Cells: A Practical Approach (Robertson, E. J., ed) pp. 71-112, IRL Press Lid. Oxford

27. Detloff, P. J., Lewis, J., John, S. W. M., Shehee, W. R., Langenbach, R. Maeda, N., and Smithies, O. (1994) Deletion and replacement of the mouse Adult $\beta$-globin genes by a "plug and socket" repeated targeting strategy. Mol. Cell. Biol. 14, 6936-6943

28. Newman, E. M., Nierenberg, D. W., and Santi, D. V. (1983) Selective killing of transformed cells by methotrexate with histidine depreivation of with $\alpha$-amino acids. Cancer Res. 43, 4703-4708

29. Warrington, R. C., and Fang, W. D. (1989) L-histidinol improves the selectivity and efficacy of alkylating agents and daunomycin in mice the P388 leukaemia. Br. J. Cancer 60, 652-656

30. Warrington, R. C., Cheng, I., and Fang, W. D. (1994) Susceptibility of human colon carcinoma cells to anticancer drugs is enhanced by L-histidinol. Anticancer Res. 14, 367-372

31. Johnson, K. A., Lerner, C. P., Lacio, L. C. D., Laird, P. W., Sharpe, A. H., and Simpson, E. (1995) Transgenic mice for the preparation of hygromycinresistant primary embryonic fibroblast feeder layers for embryonic stem cell selections. Nucleic Acids Res. 23, 1273-1275

32. Gossler, A., Doetschman, T., Korn, R., Sergling, E., and Kemler, R. (1986) Transgenesis by means of blastocyst derived embryonic stem cell lines. Proc. Natl. Acad. Sci. USA 83, 9065-9069

Received for publication May 16, 1996 Accepted for publication July 26, 1996. 